\title{
COMPOSTOS VOLÁTEIS EM MÉIS FLORAIS
}

\author{
Carlos Alberto Bastos De Maria* e Ricardo Felipe Alves Moreira \\ Departamento de Ciências Fisiológicas, Instituto Biomédico, Universidade do Rio de Janeiro, Rua Frei Caneca 94, $4^{\circ}$ andar, \\ 20211-040 Rio de Janeiro - RJ
}

Recebido em 20/2/02; aceito em 17/6/02

\begin{abstract}
VOLATILE COMPOUNDS IN FLORAL HONEYS. A review about origin, composition and importance of volatile compounds in floral honeys is presented. Hydrocarbons, aromatic components, acids, diacids, terpenoids, ketones, aldehydes, esters and alcohols have been found in honey aroma of different botanical origin. Cis-rose oxide has been proposed as an indicator for Tilia cordata honey. Citrus honeys are known to contain methyl anthranilate, a compound which other honeys virtually lack. Linalool, phenylethylalcohol, phenylacetaldehyde, p-anisaldehyde and benzaldehyde are important contributors for the aroma of different unifloral honeys. Both isovaleric acid, gama-decalactone and benzoic acid appears to be important odourants for Anarcadium occidentale and Croton sp. honeys from Brazil. The furfurylmercaptan, benzyl alcohol, delta-octalactone, eugenol, phenylethylalcohol and guaiacol appear to be only relevant compounds for Anarcadium occidentale. The vanillin was considered an important odourant only for Croton sp..
\end{abstract}

Keywords: volatile compounds; aroma; floral honeys.

\section{INTRODUÇÃO}

O mel é um produto de origem animal de alto valor nutritivo e com propriedades medicinais (ex. antioxidativa e asséptica), geralmente relacionadas à presença de compostos fenólicos e à enzima glicose oxidase, a qual catalisa a oxidação da glicose, com concomitante produção de peróxido de hidrogênio, um forte agente oxidante que ataca o envoltório de microrganismos. Para a produção de mel, as abelhas usam como matéria-prima, principalmente, o néctar cuja origem advém do fluido circulante de plantas vasculares. Esse fluido que distribui nutrientes para o tecido vegetal é oriundo de dois sistemas: floema (sistema vascular que conduz matéria-orgânica) e xilema (sistema vascular que conduz água e minerais) ${ }^{1}$.

O mel floral pode ser monofloral quando o néctar é, predominantemente, originário de uma única fonte floral, ou polifloral se mais de uma espécie vegetal contribui, de forma expressiva, com o néctar ${ }^{2}$. A caracterização de um mel monofloral é baseada na identificação morfológica e quantificação dos grãos de pólen, os quais são carreados involuntarialmente junto com o néctar, quando da visita das abelhas aos nectários florais. Na prática, não é possível se obter um mel 100\% monofloral, ou seja, isento de grãos de pólen de outros espécimes. $\mathrm{O}$ aroma é um dos atributos sensoriais mais apreciados pelos consumidores de mel. O perfil de compostos voláteis representativos desse aroma serviria como método complementar para atestar a autenticidade do mel monofloral, bem como auxiliar no monitoramento da qualidade básica do produto.

Este trabalho tem como objetivo realizar uma revisão crítica sobre compostos voláteis representativos de méis florais. São abordados aspectos sobre composição, uso como indicador de origem geográfica e botânica e, também, a qualidade odorífera e o seu impacto para o aroma do mel.

\section{COMPOSTOS VOLÁTEIS}

Os compostos de aroma podem ser originados de: 1- transferên-

*e-mail: carreb@uol.com.br cia de constituintes voláteis da planta; 2- conversão de constituintes da planta pela abelha; 3- a produção de compostos pelas abelhas; 4produção de compostos durante o processamento pós-colheita; 5ação de microrganismos. No primeiro caso, terpenóides como 3,9epoxi-1,4(8)-p-mentadieno, derivados do linalol e o eugenol foram encontrados tanto nas flores como no mel de Tilia cordata (tília) ${ }^{3}$. As enzimas da classe reductase oriundas das abelhas poderiam catalisar reações de redução onde, por exemplo, o feniletanal (fenilacetaldeído) poderia ser convertido a feniletanol (álcool feniletílico). Já compostos ácidos voláteis (ex. ácido acético e butírico) poderiam ser produzidos durante o metabolismo da abelha. A presença de aldeídos ramificados (ex. isobutanal, 2-metil-butanal), produzidos durante a reação de "Strecker"4 e compostos heterocíclicos contendo oxigênio (ex. 2-metil-furano, furfural), oriundos da caramelização de açúcares, são exemplos de artefatos produzidos durante o processamento pós-colheita e armazenamento em temperaturas inadequadas. A presença de leveduras contaminantes é responsável pelo alto teor de etanol e isobutanol, bem como de aldeídos ramificados ${ }^{5}$. As leveduras osmofílicas são encontradas com certa frequência em méis monoflorais de áreas tropicais ${ }^{6}$.

O mel é uma matriz cujos elementos majoritários são a água (cerca de 20\%) e os glicídeos (70\%), particularmente, a glicose e a frutose e onde, também, coexistem pequenas quantidades de oligossacarídeos, predominando, particularmente, a sacarose e a maltose ${ }^{1}$. Os compostos minoritários são compostos fenólicos, aminoácidos, vitaminas, sais minerais e ácidos orgânicos. Embora essa matriz seja, aparentemente, pouco complexa, existem dificuldades para o isolamento de compostos voláteis, responsáveis pelo aroma do mel. A mais comum é a grande quantidade de monossacarídeos que favorece as reações de escurecimento não enzimático. Portanto, o isolamento e o enriquecimento da fração volátil não deve ser realizado com aquecimento, sob risco de se obter compostos que não estão presentes no aroma original do mel.

A primeira análise de compostos voláteis foi realizada em 19297. Desde então, mais de 300 compostos foram identificados em méis monoflorais de diversos tipos florais ${ }^{8,9}$. A partir de 1960, a cromatografia gasosa (CG) foi usada para a análise de compostos 
voláteis em mel. Dorrscheidt e Friedrich ${ }^{10}$ detectaram 31 picos durante a análise por CG de um destilado de mel, porém só identificaram o acetato de metila e o propionato de metila. Em outro trabalho ${ }^{11}$, um extrato etéreo foi obtido onde foram identificados o 5(hidroximetil)furfural (HMF) e compostos voláteis de baixa pressão de vapor. Estes autores noticiaram, também, que a grande maioria dos compostos com odor semelhante ao mel pertenciam à fração de baixa pressão de vapor. Os compostos voláteis de uma amostra de mel foram extraídos através do uso de uma corrente de hidrogênio a $70-90{ }^{\circ} \mathrm{C}$ por Cremer e Riedmann ${ }^{12}$ que identificaram 80 compostos, incluindo ácidos, hidrocarbonetos e ésteres. Tschosgowadse et al. ${ }^{13}$ analisaram méis provenientes da Rússia e identificaram terpenóides e ésteres, como por exemplo $\gamma$-terpineno, citronelol, nerol, linalol, mentol, formato de citronelina e acetato de linalina, os quais provavelmente originaram-se diretamente da fonte floral. Um ano depois, foi publicado um trabalho sobre a identificação do 8-p-menteno-1,2diol (componente majoritário) e mais outros 26 compostos a partir de um extrato etéreo obtido de $116 \mathrm{Kg}$ de mel de tília ${ }^{14}$.

Ferber e Nursten ${ }^{15}$ usaram CG acoplada à espectrometria de massas (EM) para estudar os compostos voláteis obtidos por destilação a vácuo. Cerca de 50 compostos foram identificados, principalmente, hidrocarbonetos e compostos aromáticos, tais como o fenilmetanol (álcool benzílico) e o álcool 2-feniletílico. Já Wootton et $a l .{ }^{16}$ estudaram os compostos voláteis de alguns méis australianos, os quais foram extraídos com acetato de etila. Cerca de 15 compostos foram identificados por CG/EM, e esses autores concluiram que a estocagem do mel ao longo de um ano reduziu, de um modo geral, o teor de compostos voláteis. Além do mais, eles verificaram que os compostos com odor semelhante ao do mel pertenciam à fração de baixa pressão de vapor, o que já havia sido verificado em um trabalho previamente publicado por Merz ${ }^{11}$. Em um outro trabalho, cerca de 160 compostos voláteis foram identificados em méis monoflorais da Austrália ${ }^{17}$. Alguns como o fenil-metanal (fenilacetaldeído), álcool benzílico e o álcool 2-feniletílico foram identificados positivamente, enquanto os outros como óxido de linalol e butirato de hexenila foram somente identificados por tentativa.

Bicchi et al. ${ }^{18}$ investigaram o aroma de méis mono- e poliflorais oriundos da região de Piemonte, na Itália. Esses autores identificaram cerca de 52 compostos por CG/EM. Foram comparadas 4 técnicas diferentes de extração dos voláteis: 1- extração e destilação simultânea com diclorometano, pelo método modificado a partir da técnica original de Likens e Nickerson ${ }^{19}$; 2- extração preliminar com acetona, para extrair grande parte dos glicídeos, antes da extração e destilação simultânea; 3- extração contínua com diclorometano em um extrator de "Soxhlet"; 4- extração a frio com acetato de etila. Foi identificada, com o $1^{\circ}$ método, uma grande quantidade de derivados do furano, provavelmente originados de reações de escurecimento não enzimático. Com o $2^{\circ}$ método, o extrato obtido foi pobre em derivados do furano e apresentou um aroma semelhante ao do mel. Os $3^{\circ}$ e $4^{\circ}$ métodos forneceram extratos com perfil de compostos voláteis bem mais pobre e o aroma de mel esteve ausente. Bicchi et $a l .{ }^{18}$ concluiram que alguns compostos voláteis estiveram presentes em todas as amostras, enquanto outros variaram de uma amostra para outra contribuindo, consideravelmente, para os aromas distintos de cada mel monofloral. Bonaga e Giumanini ${ }^{20}$ noticiaram que a 3-amino-acetofenona é o principal composto volátil do mel de Castanea sativa (castanha). Neste mesmo mel, a fração de hidrocarbonetos $\left(\mathrm{C}_{5}-\mathrm{C}_{33}\right)$ foi estudada detalhadamente.

Uma série de publicações foi realizada com o objetivo de divulgar o estudo de compostos carboxílicos aromáticos presentes no $\mathrm{mel}^{21,24}$. Enquanto uma grande quantidade de ácido fenil-láctico (acima de 200 mg/Kg mel) e ácido fenil-propiônico caracterizaram méis de Calluna vulgaris (urze) e Brassica napus (colza), respectivamen- te, o mel de Fagopyrum esculentum (trigo sarraceno) pode ser identificado pela ausência de ácido fenil-acético. Já Serra Bonvehi ${ }^{25}$ e White ${ }^{26}$ identificaram o antranilato de metila em concentrações acima de 0,05 ppm em méis de Citrus sp. (laranja e lima). Cerca de 2-4 ppm foram encontrados, particularmente, em méis de laranja. Entretanto, outros autores ${ }^{5,27}$ não detectaram o antranilato de metila em amostras de mel de laranja. Geralmente, o antranilato de metila não é encontrado em méis de outras fontes florais. Em um outro estu$\mathrm{do}^{28}$, os compostos voláteis de um mel monofloral de Leptospermum scoparium foram isolados e analisados por CG/EM. Neste ponto, é importante enfatizar que para alguns nomes triviais de espécies vegetais não existem traduções para língua portuguesa e, portanto, nestes casos, o nome científico foi usado ao longo do texto. No mel de Leptospermum scoparium cerca de 29 compostos voláteis foram identificados entre eles: derivados do linalol, compostos aromáticos, ésteres e derivados do furano ${ }^{28}$. Os autores concluíram que o mel processado a $50{ }^{\circ} \mathrm{C}$ por $16 \mathrm{~h}$ possibilitou a formação de pequenas quantidades de derivados do furano. A partir de $70^{\circ} \mathrm{C}$, foi detectado em maior quantidade o HMF. O furfural foi detectado já a $60{ }^{\circ} \mathrm{C}$ e esses autores ${ }^{28}$ reivindicaram que este composto poderia ser um melhor marcador para monitorar o superaquecimento do mel. Entretanto, o furfural é altamente reativo e, portanto, níveis mais baixos de furfural poderiam não refletir de maneira fidedigna o processamento inadequado do mel.

Uma série de estudos foram realizados com méis monoflorais da Nova Zelândia ${ }^{29-31}$. No primeiro estudo, os extratos etéreos de soluções aquosas de méis de Leptospermum scoparium, Leptospermum ericoides e Trifolium repens (trevo branco) foram obtidos por extração líquido/líquido contínua ${ }^{29}$. Os compostos foram submetidos à reação de metilação, antes de serem estudados por CG/EM e, também, por cromatografia em camada delgada preparativa seguida por análise de ressonância magnética linear $\left./{ }^{1} \mathrm{H}-\mathrm{e}{ }^{13} \mathrm{C}-\mathrm{RMN}\right)$. Os compostos identificados incluiram hidrocarbonetos $\left(\mathrm{C}_{21}-\mathrm{C}_{33}\right)$, ácidos monobásicos, dibásicos e aromáticos. Segundo os autores ${ }^{29}$, a presença de hidrocarbonetos de alta massa molecular é devida à presença de cera, a qual não seria totalmente separada durante o processamento do mel. A grande quantidade de alcanos $\mathrm{C}_{23}, \mathrm{C}_{25}, \mathrm{C}_{27}$ e $\mathrm{C}_{29}$ identificada ${ }^{29}$ foi similar aos resultados de Graddron et al. ${ }^{15}$ que estudaram méis australianos. Os ácidos graxos majoritários foram: ácido palmítico, lignocérico, oléico, $\alpha$-linolênico. Os diácidos octanodióico, nonanodióico, decanodióico e 2-decenodióico foram noticiados pela primeira vez em amostra de $\mathrm{mel}^{29}$. O ácido 2decenodióico foi o diácido de maior relevância, alcançando concentrações de 3,5-181,2 $\mu \mathrm{g} / \mathrm{g}$ mel. Este diácido seria um componente relevante do sistema de feromônio, particularmente, em relação ao controle do comportamento das abelhas operárias e para o desenvolvimento sexual das larvas. Os feromônios são compostos, geralmente, liberados no ambiente por animais, cuja principal função seria modular o comportamento de outros da mesma espécie. Os méis de Leptospermum scoparium e Leptospermum ericoides são caracterizados pela presença dos ácidos 4-hidroxi-3,5-dimetoxi-benzóico e 2-metoxi-benzóico e da 2-metoxi-acetofenona, provavelmente, oriundos da cera ${ }^{29}$. Embora os méis de Leptospermum scoparium e Leptospermum ericoides contivessem baixíssimos níveis de ácido 2hidroxi-3-fenil-propiônico, isto seria suficiente para diferenciar esses méis do mel de trevo branco. Este ácido aromático seria oriundo da metabolização da fenilalanina pelas abelhas ou por microrganismos, esta última origem já foi previamente descrita por Ehrlich e Jacobsen $^{32}$. A presença do ácido 2-hidroxi-3-fenil-propiônico em mel foi descrita pela primeira vez por Hodges e White ${ }^{33}$. Uma série de terpenóides foi identificada nas flores de Leptospermum scoparium, porém nenhum deles foram encontrados no correspondente $\mathrm{mel}^{29}$. No segundo trabalho, o mel de urze foi objeto de investigação quan- 
to ao teor de compostos voláteis ${ }^{30}$. Diferente dos méis de Leptospermum scoparium, Leptospermum ericoides e trevo branco, o mel de urze não continha diácidos. Os níveis dos ácidos benzóico e fenil-acético foram idênticos aos encontrados por Steeg e Montag ${ }^{21}$, porém a concentração de ácido 2-hidroxi-3-fenil-propiônico foi bem menor. Tan et al..$^{30}$ acharam níveis similares de derivados da 3,5,5trimetilciclohex-2-en-1-ona nas 4 amostras de méis de urze. As substâncias, possuindo estruturas deste tipo, são, freqüentemente, associadas a produtos da degradação de carotenóides, os quais são encontrados em várias plantas. Esses compostos foram achados somente em méis de urze e, provavelmente, são de origem biossintética específica desta planta. Entretanto, nenhum carotenóide, não degradado, foi detectado em mel de urze. Esses autores sugeriram que esses derivados dos carotenóides contribuem para o sabor do mel de urze $^{30}$. Em um outro trabalho ${ }^{31}$, os produtos da degradação de carotenóides também foram encontrados em méis de Thymus vulgaris (tomilho) e Salix sp. (salgueiro). Os isômeros do 1-(3-oxo-1-butenil)2,6,6-trimetil-1,2-epoxiciclo-hexan-4-ol e 1-(3-oxo-trans-1-butenil)2,6,6-trimetilciclohexano-trans,cis-1,2,4-triol foram detectados nos extratos do mel de tomilho. Já os ácidos trans, cis-abscísico e o trans,trans-abscísico foram detectados nos extratos de salgueiro ${ }^{30}$. Os trabalhos de Tan et al. ${ }^{29-31}$ contribuíram significativamente para a compreensão do aroma dos méis da Nova Zelândia, entretanto, a caracterização do tipo floral baseada em produtos de degradação e contaminantes supostamente oriundos da cera é de aplicação discutível, já que seu conteúdo pode variar consideravelmente.

Blank et al. ${ }^{3}$ estudaram o mel de tília originário da Romênia. Os compostos voláteis foram isolados por extração e destilação simultânea com pentano e éter etílico e analisados por CG/EM e ${ }^{1} \mathrm{H}-\mathrm{RMN}$. Esses autores usaram a análise da diluição do extrato de aroma (ADEA) para identificar os compostos voláteis de impacto para o aroma. Esta técnica consiste na diluição do extrato, aplicação no CG e percepção do aroma ("SNIFFING") de cada pico através de um dispositivo conectado à saída da coluna cromatográfica. $\mathrm{O}$ pico cujo odor ainda é percebido, mesmo após uma diluição acentuada, poderia ser considerado como representativo de um composto volátil de impacto para o aroma do produto. Cerca de 21 compostos apresentaram fator de diluição alto e alguns deles apresentaram aroma de mel (ex. p-anisaldeído, álcool 2-feniletílico, fenilacetaldeído, (E)- $\beta$ damascenona e eugenol). Já o trans-8-p-menten-1,2-diol foi sugerido como um composto indicador para a caracterização do mel de tília ${ }^{3}$. Os compostos voláteis de 84 méis de 14 tipos florais oriundos de 10 países foram descritos por Bouseta et al. ${ }^{5}$. Os compostos foram isolados por "headspace dinâmico" acoplado diretamente ao CG/ EM. O termo "headspace" é usado para designar a fase gasosa imediatamente acima da fase sólida ou líquida, armazenada em um recipiente hermeticamente fechado. Os compostos voláteis, oriundos da amostra mantida a $70{ }^{\circ} \mathrm{C}$ em um recipiente, foram arrastados por um fluxo de nitrogênio e adsorvidos em uma armadilha mantida a $-95{ }^{\circ} \mathrm{C}$. Após $15 \mathrm{~min}$, os compostos foram dessorvidos a $220{ }^{\circ} \mathrm{C}$. Nesse caso, o "headspace dinâmico" foi realizado no próprio injector, que é denominado de injector do tipo "purge and trap". Bouseta et $a l .{ }^{5}$ identificaram alguns compostos característicos da fonte floral, particularmente, em méis de Lavandula angustifolia (alfazema) (hexanal e heptanal), Abies sp. (abeto) (acetona), Eucaliptus sp. (eucalipto) (dicetonas, alcanos e compostos sulfurosos) e Taraxacum officinale (dente-de-leão) e colza (três compostos não identificados). Alguns compostos, tais como alcoóis (etanol, isobutanol), aldeídos ramificados e derivados do furano, refletiram mais a pureza microbiológica, o processamento e as condições de estocagem que a origem floral. Esses autores ${ }^{5}$ concluíram que outros estudos baseados em um menor número de compostos voláteis poderia ser útil para diferenciar méis monoflorais e para caracterizar melhor o aro- ma desses méis. Overton e Manura ${ }^{27}$ também empregaram o método de "headspace dinâmico" acoplado a um sistema tipo "purge and trap" para isolamento e enriquecimento de compostos voláteis de diferentes tipos florais. Esses autores ${ }^{27}$ identificaram os compostos do aroma usando a técnica de CG/EM. O sistema de captura desses compostos foi aquecido a $80{ }^{\circ} \mathrm{C}$ para reduzir a viscosidade da amostra. Cerca de 120 compostos foram identificados, tais como "lilac" aldeídos, ácidos aromáticos e monoterpenos. As estruturas químicas de um "lilac" aldeído e de um "lilac" álcool são mostradas na Figura 1. Tanto o trabalho de Bouseta et al. ${ }^{5}$ como o de Overton e Manura ${ }^{27}$ descreveram o método de "headspace dinâmico" como técnica de isolamento e enriquecimento de compostos do aroma. Em ambos os trabalhos, as amostras foram submetidas a temperaturas acima de $50{ }^{\circ} \mathrm{C}$. Na opinião dos autores desta revisão, o aquecimento das amostras acima de $30{ }^{\circ} \mathrm{C}$ favorece o aparecimento de compostos oriundos de reações de escurecimento não enzimático.

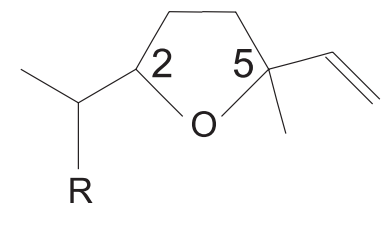

$\mathrm{R}=\mathrm{CH}_{2} \mathrm{OH}$ ("lilac" álcool)

$\mathrm{R}=\mathrm{CHO}$ ("lilac" aldeído)

Figura 1. Estrutura química de um "lilac" aldeído e de um "lilac" álcool

Os méis de Carduus nutans, oriundos da Nova Zelândia, foram estudados por Wilkins et al. $^{34}$. Cerca de 16 derivados do linalol e uma variedade de ácidos e fenóis foram identificados neste tipo floral. Os compostos voláteis foram estudados por CG/EM, CG/detector de ionização em chama (DIC) e ${ }^{13} \mathrm{C}-\mathrm{RMN}$. Os extratos etéreos forneceram 3 derivados do linalol majoritários (E)-2,6-dimetil-3,7octadien-2,6-diol, (Z)-2,6-dimetil-6-hidroxi-2,7-dienal e o ácido (E)2,6-dimetil-6-hidroxi-2,7-octadienóico. O conteúdo total de derivados do linalol, nesses méis, foi de $15-87 \mathrm{mg} / \mathrm{g}$ mel. Esses 16 derivados do linalol foram propostos com marcadores adequados para caracterização do mel de Carduus nutans. Esses autores ${ }^{34}$ também encontraram pequenas quantidades dos isômeros do $\alpha, 5$-dimetil-5etenil-2-tetrahidrofuranacetaldeídos ("lilac" aldeídos) e dos isômeros 3,5-dimetil-5-etenil-2-tetrahidrofuranetanóis ("lilac" alcóois), através da comparação com padrões. Bouseta e Collins ${ }^{35}$ aprimoraram alguns parâmetros da metodologia de extração e destilação simultânea para quantificação de compostos voláteis de méis canadenses. Em relação ao solvente, a extração com pentano foi ineficiente, porém a extração com acetona e diclorometano produziu extratos ricos em compostos voláteis. Entretanto, o extrato obtido com acetona apresentou muitos derivados do furano que, segundo essas autoras ${ }^{35}$, seriam provenientes de reações de escurecimento não enzimático com glicídeos. A glicose e a frutose são mais solúveis em acetona do que em diclometano. De fato, os derivados do furano foram encontrados em muito menor quantidade no extrato obtido com diclorometano. Todos os compostos voláteis apresentaram fator de recuperação acima de $77 \%$, quando o tempo de extração e destilação ficou no limite de 30-45 min. Bouseta e Collins ${ }^{35}$ verificaram, também, que a temperatura ideal para a condensação do tipo "dedo frio" variou de -5 a $-10{ }^{\circ} \mathrm{C}$ dependendo da característica de cada composto volátil. Essas autoras também determinaram o impacto do oxigênio sobre a recuperação de compostos voláteis do mel. Um fluxo de nitrogênio de 2 $\mathrm{mL} / \mathrm{min}$ favoreceu a recuperação de compostos voláteis como o 
canfeno e o $\beta$-pineno, porém o aumento do fluxo para $60 \mathrm{~mL} / \mathrm{min}$ reduziu, consideravelmente, a recuperação desses compostos devido à redução da eficiência no processo de condensação via "dedo frio" 35 . Segundo essas autoras, o método não é recomendado para compostos hidrofílicos como os alcoóis (ex. álcool benzílico, álcool feniletílico e álcool furfurílico), em função dos fatores de recuperação serem baixos. Esse método também não é recomendado para $\mathrm{C}_{4}$ $\mathrm{C}_{5}$ lactonas pelo fato dessas moléculas possuirem instabilidade térmica alta.

Rowland et al. ${ }^{36}$ compararam a composição dos extratos etéreos do mel de Eucryphia lucida com aqueles das flores e folhas desta planta. O hotrienol (3,7-dimetil-1,5,7-octatrien-3-ol) foi o principal composto do aroma detectado por análise de "headspace" obtido deste mel. Segundo esses autores ${ }^{36}$, esse composto foi oriundo da desidratação do 2,6-dimetil-3,7-octadien-2,6-diol, o principal terpeno encontrado nos extratos do mel de Eucryphia lucida. Este diálcool foi detectado nos extratos da planta. $\mathrm{O}$ acetato de 2-hidroxi-2-(4-metoxifenila) foi achado neste tipo de mel; este composto não foi detectado em nenhuma outra variedade de mel monofloral. Este último, juntamente com um composto não identificado, foram os principais componentes detectados neste tipo de mel ainda não totalmente maduro, entretanto não foram detectados nos extratos das plantas. $\mathrm{O}$ mel é considerado maduro quando, geralmente, mais do que $50 \%$ dos opérculos estão totalmente fechados e o conteúdo de umidade e sacarose, geralmente, não excede a $18 \%$ e $5 \%$, respectivamente. Rowland et $a l .{ }^{36}$ também detectaram outras classes de compostos neste tipo de mel (ex. hidrocarbonetos $\mathrm{C}_{21}-\mathrm{C}_{31}$, ácidos graxos $\mathrm{C}_{16}-\mathrm{C}_{28}$ e diácidos). Bouseta et $a l .{ }^{37}$ estudaram 110 méis de alfazema e eucalipto originários de 4 países diferentes. Cerca de 57 compostos foram isolados por destilação e extração simultânea e identificados por CG/DIC e CG/EM. Os aldeídos lineares, o n-hexanol, a cumarina e o fenilacetaldeído foram os principais compostos voláteis em mel de alfazema, enquanto decetonas, hidroxi-cetonas, 3-hexanol, compostos sulfurosos e alcanos foram os mais relevantes em méis de eucalipto. Alguns compostos foram apontados como característicos de cada mel monofloral. A presença de caproaldeído e heptanal na concentração de 279-1.162 ppb, respectivamente, foram considerados característicos do mel de alfazema. Esses resultados ${ }^{37}$ confirmaram aqueles obtidos por Bouseta et $a l .{ }^{4}$ que usaram "headspace dinâmico". A presença de fenilacetaldeído e cumarina em concentrações acima de 0,822 ppm e 0,512 ppm, respectivamente, também foi um aspecto marcante dos méis de alfazema. O fenilacetaldeído sozinho não é um bom indicador para mel de alfazema, já que outros tipos florais também contém esse composto volátil. Segundo esses autores ${ }^{37}$, não existem citações anteriores sobre a presença de cumarina em méis monoflorais. Uma concentração elevada de octano (acima de $344 \mathrm{ppb}$ ) e nonano (acima de $73 \mathrm{ppb}$ ), respectivamente, foi encontrada em méis de eucalipto o que corroborou os dados obtidos por outros autores ${ }^{5,17}$. A diacetila e a 2,3-pentanodiona foram, também, apontadas como típicas de méis de eucalipto ${ }^{35}$, como já noticiado previamente ${ }^{5}$. A presença de 3,4-hexanediona, ao nível de $34 \mathrm{ppb}$ a 13,5 ppm, também foi um bom marcador para esse mel monofloral. Sua presença correlacionou com concentrações elevadas de hidroxi-butanona (acetoína) (1,8-26,1 ppm), de 2,5-hexanediol (14-54 ppb) e o 3-hexanol (42 ppb-18,5 ppm). Uma concentração elevada de dissulfeto de dimetila (123-1.667 ppb) foi achada em todos os méis de eucalipto, embora nenhum aminoácido sulfuroso tenha sido encontrado nessas amostras.

Shimoda et al. ${ }^{38}$ isolaram os compostos voláteis de um extrato aquoso de mel de Rhus succedanea (avelã). Esses compostos foram isolados por cromatografia de adsorção, usando-se "Porapak Q" como adsorvente e éter etílico como solvente para dessorção. Esses autores concluíram que o extrato, obtido com o método supracitado, forneceu um aroma mais intenso de mel quando comparado à extração preliminar com acetona, seguida pela técnica de extração e destilação simultânea. Foi identificado um total de 120 compostos voláteis, incluindo 27 alcoóis, 19 aldeídos, 9 cetonas, 12 ésteres, 8 ácidos, 35 hidrocarbonetos, 10 furanóides ou piranóides e 10 outros compostos. A importância sensorial dos compostos voláteis foi investigada por "SNIFFING" de frações isoladas do eluato obtido da cromatografia de adsorção, separadas por CG preparativa ${ }^{38}$. A fração 1 apresentou um odor suave de fruta. $\mathrm{O}$ acetato de etila, o acetato de butila e outros ésteres contribuíram para o odor de fruta. Ao lado destes ésteres, os aldeídos alifáticos, tais como n-hexanal e n-heptanal, também, contribuíram parcialmente para o aroma de fruta. A fração 2 apresentou um odor floral fraco. Do ponto de vista quantitativo, os óxidos do linalol (ambos trans-furanóide e cis-furanóide) foram os principais compostos desta fração. Entretanto, esses compostos apresentaram um alto limite de detecção, significando que concentrações muito altas seriam necessárias para a percepção de algum odor. O n-nonanol, o benzaldeído e o linalol seriam responsáveis pelo odor da fração 2, já que apresentaram um baixo limite de detecção. As frações 3 e 4 apresentaram um aroma semelhante ao do mel. Em relação à fração 3, o 2,6-dimetil-1,3,7-octatrien-6-ol ${ }^{38}$, com um cheiro doce e floral conforme noticiado por Nakatani et al. ${ }^{39}$; o fenilacetaldeído, com odor de mel segundo Blank et al. ${ }^{3} ; \gamma$ octalactona, com um odor doce; o 4-etil-benzaldeído, com um odor doce, semelhante ao de amêndoa e com nota floral ${ }^{3}$; o salicilato de etila, com odor de menta refrescante e o guaiacol, com odor de fumaça ${ }^{40}$, foram os principais responsáveis pelo aroma da fração 3 . Três isômeros do "lilac" aldeído foram identificados por tentativa com base nos resultados de Wilkins et al. ${ }^{34}$. Lamentavelmente, os autores não forneceram qualquer informação sobre esses três isômeros ${ }^{38}$. Estes compostos também contribuíriam para o aroma da fração 3. Shimoda et al. ${ }^{38}$ descreveram a fração 4 como a mais importante. Nesta fração, o álcool feniletílico, com um odor floral intenso ${ }^{40}$; isômeros do p-anisaldeído com um aroma doce e de especiarias e o trimetoxi-benzeno, com um odor pungente e doce, poderiam contribuir para o aroma. Uma grande quantidade de panisaldeído foi encontrada neste mel, o que fez com que esses autores $^{38}$ sugerissem este composto como de impacto para o aroma de mel de avelã. Blank et al. ${ }^{3}$ também indicaram este composto como de impacto para o aroma de mel de Tília. A 5-hidroxi-2-metil-4Hpiran-4-ona poderia contribuir para o odor doce da fração 4 por causa que seu isômero, o 3-hidroxi-2-metil-4H-piran-4-ona (maltol), tem um forte odor doce. Na opinião dos autores dessa revisão, esse composto seria oriundo da pirólise de monossacarídeos, presentes em grande quantidade no mel (acima de $60 \mathrm{~g} \%$ ), ocasionada pela exposição excessiva ao aquecimento durante o processamento. Portanto, não seria um composto volátil naturalmente presente nessa matriz alimentícia. Segundo Shimoda et al. ${ }^{38}$, alguns compostos não identificados tiveram um espectro similar aos "lilac" alcóois ${ }^{33}$, exceto para o fragmento m/z 75, o qual sugeriu a presença de análogos acetais dos "lilac" aldeídos. Para esses autores, a fração 5 forneceu constituintes com pouca importância sensorial para o mel de avelã.

Guidotti e Vitali ${ }^{41}$ investigaram os compostos voláteis de 18 amostras de méis monoflorais de alguns tipos florais diferentes, com o intuito de caracterizar a origem floral com base na identificação de alguns compostos voláteis específicos. Esses autores usaram a técnica de micro-extração em fase sólida ("SPME") para isolar e concentrar os compostos voláteis. Cerca de $3 \mathrm{~g}$ de cada amostra de mel foram aquecidos em banho-maria a $70{ }^{\circ} \mathrm{C}$ por $30 \mathrm{~min}$. Em seguida, a seringa de "SPME" foi introduzida no tubo e mantida por $20 \mathrm{~min}$ a $70{ }^{\circ} \mathrm{C}$. Após esse tempo, esta foi retirada e aplicada no CG/EM e mantida no injetor por $3 \mathrm{~min}$. Cerca 20-30 compostos voláteis foram identificados nos méis monoflorais. $\mathrm{O}$ resultado mais importante foi que o nonanol e o ácido palmítico foram encontrados exclusivamente em méis de 
eucalipto. Entretanto, esses compostos não foram, previamente, citados por outros autores ${ }^{5,17,37}$, como característicos de méis de eucalipto. Serra et al ${ }^{42}$ caracterizaram a fração volátil dos méis de Fragaria vesca (morango) oriundos de algumas regiões da Sardenha. O isolamento e enriquecimento da fração volátil foi realizado pela aplicação de um extrato aquoso do mel em uma resina XAD-2. A dessorção foi feita pela passagem de uma solução azeotrópica de pentano-diclorometano $(2: 1, \mathrm{v} / \mathrm{v})$, cujo eluato foi concentrado por destilação. O extrato concentrado foi, então, aplicado no CG/EM. Segundo esses autores ${ }^{42}$, o extrato teve um aroma semelhante ao da amostra original. Foi identificada uma grande quantidade de norisoprenóides polioxigenados com esqueleto $\mathrm{C}_{9}-\mathrm{C}_{13}$ (ex. vomifoliol e desidrovomifoliol). As estruturas químicas desses compostos são mostradas na Figura 2. Este grupo de compostos também foi achado no mel de urze; tanto o mel de morango como o de urze pertencem à família Ericaceae. Entretanto, a distribuição quantitativa desses norisoprenóides serve para diferenciar os 2 tipos monoflorais. A 1-(3-hidroxi-1-oxobutil)-2,2,6-trimetil-7oxabiciclo [4.1.0]heptan-4-ona foi considerada de relevância para uma provável caracterização do mel de morango. Este composto foi melhor identificado pela análise dos espectros oriundos do infra-vermelho com transformada de Fourier. Também a 3,5,5-trimetil-3ciclohexen-1-ona, a 1,3,3-trimetil-7-oxabiciclo[4.1.0] heptane-2,5diona, a 3,5,5-trimetil-3-ciclohexene-1,2-diona e a 2,2,6-trimetil-1,4ciclohexanediona foram consideradas marcadores específicos para o mel de morango. Serra et al. ${ }^{42}$ concluíram, com base em seus resultados, que o método químico foi válido para avaliar a pureza do mel de morango.

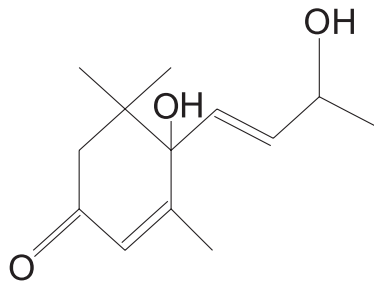

A

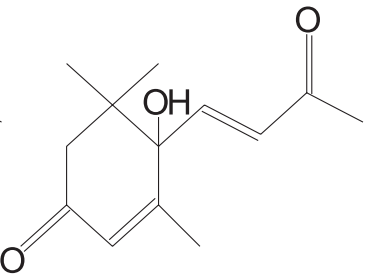

B
Figura 2. Estrutura química do vomifoliol (A) e do desidrovomifoliol (B)

Radovic et al $^{43}$ estudaram o perfil de compostos voláteis de 43 amostras de méis de diferentes tipos florais e originários de alguns países da Europa, com o objetivo de identificar marcadores específicos. Foi usada a CG/EM para identificação dos compostos do aroma. Em geral, aldeídos lineares e ramificados, cetonas e alcoóis de massa molecular baixa foram achados na maioria dos tipos florais. A presença de óxido de cis-linalol e de heptanal e a ausência de fenilacetaldeído e de dissulfeto de dimetila seriam marcadores específicos para o mel de Acacia sp. (acácia). Já a presença de 2-metildihidrofuranona ou álcool 2-metil-benzílico ou a presença simultânea de 3-hexen-1-ol e dimetil-estireno caracterizaria o mel de castanha. A 3-aminoacetofenona, que foi apontada como um composto característico de mel de castanha ${ }^{20}$, não foi encontrada em $30 \%$ das amostras de mel de castanha analisadas por Radovic et al..$^{43}$. A presença de 1-octeno ou 2,3-pentanodiona seria específica do mel de eucalipto. Graddon et al. ${ }^{17}$ apontaram as hidroxicetonas como características de méis de eucalipto, o que não foi confirmado por Radovic et al. ${ }^{43}$. Já Guidotti e Vitali ${ }^{41}$ identificaram o nonanol e o ácido palmítico como característicos do mel de eucalipto. Essas diferenças parecem ser reflexo das diversas origens geográficas. Um outro fator que poderia contribuir para essa diferenças seria o uso de métodos distintos de isolamento e enriquecimento do aroma. A presença de biciclo-2,2,2-4-metil-octan-1-ol ou o acetato de 4-etil-fenila seriam característicos de mel de urze ${ }^{42}$. Uma concentração elevada de ácido fenil-láctico (acima de $200 \mathrm{mg} / \mathrm{Kg}$ mel) foi noticiada nesse tipo floral por Steeg e Montag ${ }^{21}$, porém Radovic et $a l .{ }^{43}$ não confirmaram esses resultados. Tan et $a l .{ }^{30}$ sugeriram a presença de produtos da degradação de carotenóides (derivados do 3,5,5trimetil-cicloex-2-eno) em méis de urze, entretanto eles também não foram identificados nas amostras analisadas por Radovic et al. ${ }^{43}$. Bouseta et $a l .{ }^{5}$ identificaram hexanal e heptanal como característicos de mel de urze, porém Radovic et al. ${ }^{43}$ só confirmaram esse resultado para aqueles originados da França, enquanto que nas amostras de Portugal esses compostos não foram identificados. De fato, Bouseta $e t$ $a l .{ }^{5}$ analisaram os méis de urze oriundos, exclusivamente, da França. A avaliação qualitativa de méis de alfazema indicou que a presença de heptanal e a ausência de 4-oxoisoforona seriam marcadores deste tipo floral $^{43}$. Já a presença de dissulfeto de dimetila e a ausência de 2-metil1-propanol seriam característicos de mel de colza. A ausência de 2acetil-furano seria um marcador para o mel de Rosmarinus officinalis (alecrim). Com relação ao mel de Helianthus annuus (girassol), a presença de $\alpha$-pineno ou 3-metil-2-butanol e a ausência simultânea de heptanal e 4-oxoisoforona seriam seus principais marcadores. Radovic et al. ${ }^{43}$ também analisaram possíveis marcadores, principalmente, para méis da Dinamarca e Inglaterra. Eles concluíram que a presença de 1penten-3-ol foi típico de méis da Inglaterra, enquanto que a ausência de 3-metil-butanal foi característica de méis da Dinamarca.

O estudo do perfil de compostos voláteis de méis do Brasil é muito recente e, portanto, os resultados ainda são escassos ${ }^{44,45}$. O primeiro trabalho foi realizado com méis de eucalipto e laranja do Estado de São Paulo"4. Foi usado um método de "headspace dinâmico" baseado na técnica desenvolvida por Franco e RodriguezAmaya ${ }^{46}$. O tempo de captura em "Porapak Q" foi de 3 h e a dessorção dos compostos voláteis foi realizada com acetona ${ }^{44}$. Um total de 5 e 8 compostos voláteis foram identificados por CG/EM nos méis de eucalipto e laranja, respectivamente. O nonanal foi detectado com maior porcentagem relativa no mel de eucalipto recém extraído do favo. O nonanal e o nonanol, o qual foi identificado por tentativa, foram considerados compostos de grande relevância para o mel de eucalipto, com descrição sensorial de eucalipto e queimado, respectivamente. $\mathrm{O}$ nonanol foi descrito por Guidotti e Vitali ${ }^{41}$ como um possível marcador para caracterização de méis de eucalipto, porém não por outros autores ${ }^{5,17,37}$. Já o fenilacetaldeído, detectado como um composto majoritário no mel de laranja recém extraído do favo, apresentou uma diminuição na sua abundância relativa no mel comercializado. Este composto e o benzaldeído teriam uma participação importante para o aroma do mel de laranja ${ }^{44}$. Overton e Manura $^{27}$ também identificaram o fenilacetaldeído e o benzaldeído em méis de laranja, porém Bouseta et al..$^{5}$ não detectaram nenhum desses 2 compostos. O benzaldeído também foi apontado como um composto importante para o aroma de mel de avelã $\tilde{a}^{38}$, enquanto o fenilacetaldeído foi considerado de relevância para os méis de ave$1 \tilde{a}^{38}$ e tília ${ }^{3}$. Na opinião desses revisores, o número reduzido de compostos identificados nesse trabalho ${ }^{44}$ poderia ser útil na caracterização do tipo floral, porém restringiria a identificação de compostos voláteis de impacto para a matriz alimentícia. Em nossa opinião, a identificação de compostos voláteis de grande abundância e, ao mesmo tempo, considerados de importância para o aroma dos méis de eucalipto e laranja oriundos do Estado de São Paulo ${ }^{44}$, é um resultado inesperado já que, geralmente, os compostos voláteis de importância sensorial estão presentes em concentração muito baixa.

Recentemente, Moreira et al. ${ }^{45}$ estudaram os compostos do aroma de méis monoflorais de Anacardium occidentale (caju) e Croton sp. (marmeleiro), ambos oriundos do Nordeste brasileiro. Esses méis monoflorais são tipicamente brasileiros, já que essas plantas são nativas do Brasil. Nesse ponto, é importante ressaltar 
que o Croton sp., popularmente conhecido como marmeleiro no Nordeste, não deve ser confundido com a espécie Cydonia vulgaris, que também é conhecida como marmeleiro, a qual é encontrada na região do cerrado mineiro. Somente a última espécie, oriunda da Ásia e bem aclimatada no Brasil, produz frutos que são conhecidos como marmelos. Esses autores ${ }^{45}$ isolaram a fração volátil dos méis de caju e marmeleiro através de extração em fase sólida do extrato aquoso com o adsorvente "Porapak Q". Os compostos foram dessorvidos com acetona. Durante todo o processo de isolamento e enriquecimento da fração volátil a temperatura se manteve entre 20$25{ }^{\circ} \mathrm{C}$, minimizando a formação de artefatos. Antes da etapa de dessorção, a coluna foi lavada com água para dessorção prévia de glicídeos, já que eles são relativamente solúveis em acetona. O mel de caju apresentou cerca de $82 \%$ mais compostos voláteis que o mel de marmeleiro. Cerca de $50 \%$ dos compostos voláteis identificados por CG/EM foram confirmados com padrões ${ }^{45}$. As principais classes de compostos identificadas no mel de caju foram hidrocarbonetos (19), alcoóis (13), ácidos (6) e compostos aromáticos (6); já no mel de marmeleiro foram alcoóis (12), ácidos (5), ésteres (3) e compostos aromáticos (3). O mel de caju apresentou um alto teor de hidrocarbonetos, enquanto somente o pentacosano foi identificado no mel de marmeleiro. Em contrapartida, 6 derivados do linalol, por exemplo isômeros cis-e trans-furanóides do óxido de linalol, foram identificados no mel de marmeleiro, enquanto que no mel de caju somente um deles (trans-furanóide do óxido de linalol). A técnica de "SNIFFING" foi usada juntamente com a ADEA para identificação de compostos voláteis de relevância para os méis de caju e marmeleiro ${ }^{45}$. O butirato de butila, o guaiacol e o furfuril mercaptano (caju), o linalol (marmeleiro), o mentol, o ácido isovalérico, a deltaoctalactona, a gama-decalactona e o eugenol (caju e marmeleiro) foram identificados por tentativa através da comparação da análise de "SNIFFING" das amostras com aquela de padrões. Nenhum desses compostos foi identificado por CG/EM. A partir da ADEA, foi possível identificar 4 compostos de relevância no mel de marmeleiro: o ácido isovalérico, o ácido benzóico, a gama-decalactona e a vanilina, todos com um fator de diluição de 16. A vanilina e o ácido benzóico também foram identificados por CG/EM. Já no mel de caju foram considerados de relevância os seguintes compostos: o furfurilmercaptano, o álcool benzílico, a delta-octalactona, a gamadecalactona, o eugenol e o ácido benzóico, todos com um fator de diluição de 16, o ácido isovalérico, com um fator de 32, o álcool feniletílico, com um fator de 128 e o guaiacol, com um fator de 1024 . $\mathrm{O}$ álcool feniletílico, o álcool benzílico e o ácido benzóico também foram identificados por CG/EM. Foram detectados alguns outros odores agradáveis em ambos os méis, porém todos com um baixo fator de diluição (FD) (ex. ácido benzenoacético, FD = 0; butirato de butila $\mathrm{FD}=8$, todos no mel de caju; linalol, $\mathrm{FD}=0$, presente no mel de marmeleiro $)^{45}$. Na Tabela 1 , os compostos voláteis de impacto, sugeridos por diferentes autores, para alguns méis monoflorais, são mostrados. Outros trabalhos científicos devem ser realizados, para

Tabela 1. Compostos voláteis de impacto para alguns méis monoflorais

\begin{tabular}{|c|c|c|c|c|c|}
\hline Mel & Nome científico & País & Composto & Método de isolamento & Ref. \\
\hline Tília & Tilia cordata & Romênia e China & $\begin{array}{l}\text { p-anisaldeído, 1-hexen-3-ona, álcool } \\
\text { 2-feniletílico, fenilacetaldeído, } \\
\text { (E)- } \beta \text {-damascenona, eugenol, } \\
\text { vanilina, 2-acetil-1-pirrolina, } \\
\text { trissulfeto de dimetila, metional, } \\
\text { linalol, 4-vinilguaiacol, } \\
\text { 4-metilacetofenona }\end{array}$ & $\begin{array}{l}\text { extração e destilação } \\
\text { simultânea com pentano } \\
\text { e éter etílico }\end{array}$ & 3 \\
\hline
\end{tabular}

\begin{tabular}{|c|c|c|c|c|c|}
\hline Acácia & Acacia sp. & Hungria e China & $\begin{array}{l}\text { p-anisaldeído, álcool 2-feniletílico, } \\
\text { fenilacetaldeído, (E)- } \beta \text {-damascenona, } \\
\text { eugenol, vanilina, 2-acetil-1-pirrolina, } \\
\text { trissulfeto de dimetila, metional, linalol, } \\
\text { 4-vinilguaiacol }\end{array}$ & $\begin{array}{l}\text { extração e destilação } \\
\text { simultânea com pentano } \\
\text { e éter etílico }\end{array}$ & 3 \\
\hline Urze & Calluna vulgaris & Noruega & $\begin{array}{l}\text { p-anisaldeído, álcool 2-feniletílico, } \\
\text { fenilacetaldeído, (E)- } \beta \text {-damascenona, } \\
\text { eugenol, vanilina, 2-acetil-1-pirrolina, } \\
\text { metional, 4-vinilguaiacol }\end{array}$ & $\begin{array}{l}\text { extração e destilação } \\
\text { simultânea com pentano } \\
\text { e éter etílico }\end{array}$ & 3 \\
\hline Avelã & Rhus succedanea & Japão & $\begin{array}{l}\text { fenilacetaldeído, linalol, álcool } \\
\text { 2-feniletílico, p- cresol, p-anisaldeído, } \\
\text { trimetoxibenzeno, "lilac" aldeídos, } \\
\text { 5-hidroxi-2-metil-4H-piran-4-ona }\end{array}$ & $\begin{array}{l}\text { cromatografia de } \\
\text { adsorção do extrato } \\
\text { total com porapak Q } \\
\text { e éter etílico }\end{array}$ & 36 \\
\hline Laranja & Citrus sp. & Brasil & fenilacetaldeído, benzaldeído & $\begin{array}{l}\text { "headspace" dinâmico } \\
\text { com Porapak Q e acetona }\end{array}$ & 42 \\
\hline Eucalipto & Eucaliptus sp. & Brasil & nonanal, nonanol & $\begin{array}{l}\text { "headspace" dinâmico } \\
\text { com Porapak Q e acetona }\end{array}$ & 42 \\
\hline Caju & $\begin{array}{l}\text { Anacardium } \\
\text { occidentale }\end{array}$ & Brasil & $\begin{array}{l}\text { furfurilmercaptano, álcool benzílico, } \\
\text { delta-octalactona, gama-decalactona, } \\
\text { eugenol, ácido benzóico, ácido } \\
\text { isovalérico, álcool 2-feniletílico, } \\
\text { guaiacol }\end{array}$ & $\begin{array}{l}\text { cromatografia de adsorção } \\
\text { do extrato total com } \\
\text { Porapak Q e acetona }\end{array}$ & 43 \\
\hline Marmeleiro & Croton sp. & Brasil & $\begin{array}{l}\text { ácido isovalérico, ácido benzóico, } \\
\text { gama-decalactona, vanilina }\end{array}$ & $\begin{array}{l}\text { cromatografia de adsorção } \\
\text { do extrato total com } \\
\text { Porapak Q e acetona }\end{array}$ & 43 \\
\hline
\end{tabular}


que sejam obtidas informações adicionais sobre os compostos voláteis de impacto para o aroma dos méis de caju e marmeleiro e, também, de outros méis monoflorais brasileiros.

\section{AGRADECIMENTOS}

Os autores agradecem o apoio da Fundação Carlos Chagas Filho de Amparo à Pesquisa do Rio de Janeiro (FAPERJ), do Conselho Nacional de Desenvolvimento Científico e Tecnológico (CNPq) e da Coordenação de Aperfeiçoamento de Pessoal de Nível Superior (CAPES).

\section{REFERÊNCIAS}

1. Doner, L. W.; J. Sci. Food Agric. 1977, 28, 443.

2. Barth, O. M.; Journal of the Brazilian Association for the Advancement of Science 1996, 48, 163.

3. Blank, I.; Fischer K.-H.; Grosch W.; Z. Lebensm. Unters. Forsch. 1989, $189,426$.

4. Hodge, J. E.; Agric. Food Chem. 1953, 15, 928.

5. Bouseta, A.; Collin S.; Dufour J.-P.; J. Apic. Res. 1992, 31, 96.

6. Tilbury, R. H.; Em Biological and activities of yeasts; Skinner, F. A.; Passmore, S. M.; Davenport, R. R., ed., 1st ed., Academic Press, London:U.K., 1980, p.153.

7. Schmalfub, H.; Barthmeier, H.; Biochem. Z. 1929, 216, 330.

8. Maga, J. A.; Lebensm. Wiss. Technol. 1983, 16, 65.

9. Van Straten, S.; Maarse, H.; Volatile compounds in food, 5th ed., Division for Nutrition and Food Research, TNO, Zeist: The Netherlands, 1983.

10. Dorrscheidt, W.; Friedrich, K.; J. Chromat. 1962, 7, 13

11. Merz, J. H.; J. Apic. Res. 1963, 2, 55.

12. Cremer, E.; Reidmann, H.; Z. Naturf. 1964, 19b, 76.

13. Tschogowadse, Sch.K.; Koblianidse, G. L.; Dembizkii, A. D.; Lebensm. Ind. 1973, 20, 225.

14. Tsuneya, T.; Shibai, T.; Yoshioka, A.; Shiga, M.; Koryo 1974, 109, 29.

15. Ferber, C. E. M.; Nursten, H. E.; J. Sci. Food Agric. 1977, 28, 511.

16. Wootton, M.; Edwards, R. A.; Faraji-Haremi, R.; Williams, P. J.; J. Apic. Res. 1978, 17, 167.
17. Graddon, D.; Morrison, J. D.; Smith, J. F.; J. Agric. Food Chem. 1979, $27,832$.

18. Bicchi, C.; Belliardo, F.; Frattini, C.; J. Apic. Res. 1983, 22, 130.

19. Likens, S. T.; Nickerson, G. B.; ASBC Proc. 1964, 5.

20. Bonaga, G.; Giumanini, A.G.; J. Apic. Res. 1986, 25, 113.

21. Steeg, E.; Montag, A.; Z. Lebensm. Unters. Forsch. 1987, 184, 17.

22. Steeg, E.; Montag, A.; Dtsch. Lebensm.-Rundsch.1988, 84, 103.

23. Steeg, E.; Montag, A.; Dtsch. Lebensm.-Rundsch.1988, 84, 147.

24. Steeg, E.; Montag, A.; Z. Lebensm. Unters. Forsch. 1988, 187, 115.

25. Serra Bonvehi, J.; Alimentaria 1988, 25, 37.

26. White, J. W.; Em Honey, a comprehensive survey; Crane, E. ed., 2nd ed., Heinemann, London: UK, 1975, p. 157.

27. Overton, S. V.; Manura, J. J.; Am. Lab. 1994, 45

28. Visser, F. R.; Allen, J. M.; Shaw, G. J.; J. Apic. Res. 1988, 27, 175.

29. Tan, S.-T.; Holland P.T.; Wilkins, A. L.; Molan, P. C.; J. Agric. Food Chem. 1988, 36, 453.

30. Tan, S.-T.; Holland P.T.; Wilkins, A. L.; McGhie T. K.; J. Agric. Food Chem. 1989, 37, 1217

31. Tan, S.-T.; Holland P.T.; Wilkins, A. L.; McGhie T. K.; J. Agric. Food Chem. 1990, 38, 1833.

32. Ehrlich, F.; Jacobsen, K. A.; Ber. Dtsch. Chem. Ges. 1911, 44, 888.

33. Hodges, R.; White, E. P.; N. Z. J. Sci. 1966, 9, 233.

34. Wilkins, A. L.; Lu Y.; Tan, S.-T.; J. Agric. Food Chem. 1993, 41, 873.

35. Bouseta, A.; Collins, S.; J. Agric. Food Chem. 1995, 43, 1890.

36. Rowland, C. Y.; Blackman, A. J.; D’Arcy, B. R.; Rintoul, G.B.; J. Agric. Food Chem. 1995, 43, 753.

37. Bouseta, A.; Scheirman, V.; Collin, S.; J. Food Sci. 1996, 61, 683.

38. Shimoda, M.; Wu, Y.; Osajima, Y.; J. Agric. Food Chem. 1996, 44, 3913.

39. Nakatani, Y.; Sato, S.; Yamanishi, T.; Agric. Biol. Chem. 1969, 33, 967.

40. Atlas of Odor Character Profiles, ASTM Data Series DS 61, ASTM, Philadelphia: USA, 1985.

41. Guidotti, M.; Vitali, M.; Ind. Alim. 1998, 37, 351.

42. Serra A. D.; Franco, M. A.; Mattivi, F.; Ramponi, M.; Vacca, V.; Versini, G.; Ital. J. Food Sci. 1999, 11, 47.

43. Radovic, B. S.; Careri, M.; Mangia, A.; Musci, M.; Gerboles, M.; Anklam, E.; Food Chem. 2001, 72, 511.

44. Bastos, D. H. M.; Tese de Doutorado, Universidade Estadual de Campinas, Brasil, 1996.

45. Moreira, R. F. A.; Trugo, L. C.; Pietroluongo, M.; De Maria, C. A. B.; J. Agric. Food Chem. 2003, no prelo.

46. Franco, M. R. B.; Rodriguez-Amaya, D. B.; J. Sci. Food Agric. 1983, 293. 